\title{
BMJ Open Association between serum soluble corin and hyperglycaemia: a cross- sectional study among Chinese adults
}

\author{
Yan Liu, ${ }^{1,2}$ Hao Peng, ${ }^{1,2}$ Qu Zhang, ${ }^{1,2,3}$ Peipei Zhang, ${ }^{1,2}$ Yunfan Tian,, \\ Xiangqin Chao, ${ }^{3}$ Yonghong Zhang ${ }^{1,2}$
}

To cite: Liu Y, Peng $\mathrm{H}$, Zhang $Q$, et al. Association between serum soluble corin and hyperglycaemia: a crosssectional study among Chinese adults. BMJ Open 2015;5: 0009085. doi:10.1136/bmjopen-2015009085

- Prepublication history for this paper is available online To view these files please visit the journal online (http://dx.doi.org/10.1136/ bmjopen-2015-009085)

YL, HP and QZ contributed equally.

Received 16 June 2015 Revised 12 November 2015 Accepted 13 November 2015

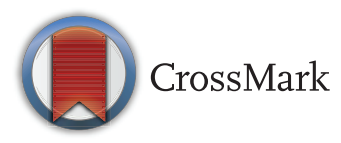

${ }^{1}$ Department of

Epidemiology, School of

Public Health, Medical

College of Soochow

University, Suzhou, China

2Jiangsu Key Laboratory of

Preventive and Translational

Medicine for Geriatric

Diseases, School of Public

Health, Soochow University,

Suzhou, China

${ }^{3}$ Center for Disease

Prevention and Control of

Gusu District, Suzhou, China

Correspondence to Dr Yonghong Zhang; yhzhang@suda.edu.cn

\section{ABSTRACT}

Objectives: Decreased natriuretic peptides are risk factors for diabetes. As a physiological activator of natriuretic peptides, corin may play a role in glucose metabolism. Here, we aimed to test the hypothesis in a general population of China.

Design: Cross-sectional study.

Setting: A population study in Suzhou, China.

Participants: A total of 2498 participants aged above 30 years were included in the study.

Outcome measures: The association between serum soluble corin and hyperglycaemia was examined in men and women, using non-conditional logistic regression models, respectively.

Results: Serum soluble corin, in men and women, was significantly higher in participants with hyperglycaemia than in those without (all $p<0.001$ ). $\mathrm{OR}$ of hyperglycaemia positively and significantly increased with serum soluble corin quartiles, in men ( $p$ for trend $<0.001$ ) and in women ( $p$ for trend $=0.050$ ), even after multivariate adjustment. Participants with a serum soluble corin, in men (OR=1.66, $95 \% \mathrm{Cl} 1.24$ to 2.23) and women ( $\mathrm{OR}=1.27,95 \% \mathrm{Cl} 1.00$ to 1.61 ), over the median level, were more likely to have hyperglycaemia compared with the remaining participants, after controlling for confounding factors.

Conclusions: Hyperglycaemia was significantly and positively associated with increased serum soluble corin in men and women. Our findings suggest that serum soluble corin may be a risk factor or a biomarker of hyperglycaemia.

\section{INTRODUCTION}

Diabetes is a major risk factor for cardiovascular disease. ${ }^{12}$ In Chinese adults, diabetes and prediabetes were highly prevalent accounting for $11.6 \%$ and $50.1 \%$, respectively, in $2010 .^{3}$ In recent decades, interventions against the traditional risk factors for diabetes have some benefit on the incidence and control of diabetes. However, the outcome of intervention has not been very satisfying. ${ }^{4} 5$ In addition, in China, only

\section{Strengths and limitations of this study}

- This is the first study to investigate the association between serum soluble corin and hyperglycaemia in a general population. In our study, we excluded participants who had a history of coronary heart disease, stroke or tumours.

- In addition to serum soluble corin, we obtained major conventional risk factors for diabetes, such as hypertension, blood lipids, body mass index, waist circumference, and lifestyle factors including alcohol consumption and cigarette smoking.

- In data analysis, all conventional risk factors obtained were controlled to reduce their confounding effects.

- A causal relationship between serum soluble corin and hypertension cannot be inferred because of the cross-sectional nature of the study design.

- We did not collect the $2 \mathrm{~h}$ oral glucose tolerance test and physical activity data. Lastly, we did not examine atrial natriuretic peptides to evaluate corin activity for our study participants.

$39.7 \%$ of patients treated with diabetes medications had adequate glycaemic control. ${ }^{3}$ This indicates that some unknown risk factors for diabetes may need to be studied.

Recently, corin, a type II transmembrane serine protease highly expressed in the heart ${ }^{6}{ }_{7}^{7}$ was found to play a physiological role in activation of atrial natriuretic peptides. $^{8-10}$ More recently, a large prospective cohort study found that a decreased level of atrial natriuretic peptides was associated with an increased risk for diabetes. ${ }^{11}$ This finding indicates a potential effect of atrial natriuretic peptides on diabetes. As a physiological activator of atrial natriuretic peptides, corin might be associated with diabetes. If so, soluble corin in the circulation may be associated with hyperglycaemia, although the mechanism of the production of corin in the 
circulation is unclear. In the literature, circulating soluble corin has been studied in some disease states, such as osteoporosis, ${ }^{12}$ heart failure, ${ }^{13}$ chronic kidney disease, ${ }^{14}$ pregnant hypertension, ${ }^{15}$ hypertension ${ }^{16}$ and obesity. ${ }^{17}$ However, to date, there has been no study on the association of soluble corin in the circulation of patients with hyperglycaemia. Here, we studied the association in a general population of China.

\section{METHODS}

\section{Study participants}

We conducted a cross-sectional study in a traditional but economically developed district of Suzhou, from January to May 2010. The participants were selected via multiphase cluster random sampling. From the total 20 urban communities and 19 rural villages in the districts, 4 urban communities and 4 rural villages were randomly selected as research fields. The participants were selected from the selected 4 urban communities and 4 rural villages. The preliminary selection criteria for eligibility were: (1) age $\geq 30$ years, (2) Han ethnicity. There were a total of 3061 eligible residents meeting the selection criteria in the study fields, but only 2706 (participating rate: 88\%) persons participated in this study. The exclusion criteria were: (1) having clinical suspicion of a disease that may cause secondary hypertension (eg, renal artery stenosis, coarctation, glomerulonephritis, pyelonephritis, phaeochromocytoma, Cushing's syndrome, Conn's syndrome), (2) selfreported history of coronary heart disease, stroke or tumours, (3) self-reported thyroid or parathyroid diseases, (4) being pregnant. After excluding 101 participants meeting the exclusion criteria and 107 participants for lacking blood samples, 2498 participants were finally included in the current analysis. This study was approved by the Soochow University Ethics Committee. Written informed consent was obtained from all study participants.

\section{Data collection}

Data on demographic information, lifestyle risk factors and personal medical history were collected with standard questionnaires in Chinese language administered by trained staff. Cigarette smoking was defined as having smoked at least one cigarette per day for 1 year or more and reported current smoking. Alcohol consumption was defined as consuming any type of alcohol beverage at least once per week during the past 3 years. Body weight and height were measured using a regularly calibrated stadiometer and balance-beam scale, with participants wearing light clothing and no shoes. Body mass index (BMI) was calculated as weight in kilograms divided by height in metres squared. Waist circumference (WC) was measured at the level of $1 \mathrm{~cm}$ above the umbilicus. Three consecutive sitting blood pressure measurements ( 3 min between each) were taken by trained staff, using a standard mercury sphygmomanometer, according to standard protocol, ${ }^{18}$ after the subjects had been resting for at least $5 \mathrm{~min}$. The first and fifth Korotkoff sounds were recorded as systolic blood pressure (SBP) and diastolic blood pressure (DBP), respectively. The mean of the three records was used in analysis.

Blood samples were obtained by venipuncture in the morning, after a requested overnight fast (at least $8 \mathrm{~h}$ ). All plasma and serum samples were frozen at $-80^{\circ} \mathrm{C}$ until laboratory testing. Fasting plasma glucose (FPG), total cholesterol (TC), triglycerides (TG), high-density lipoprotein cholesterol (HDL-C) and low-density lipoprotein cholesterol (LDL-C) were examined for all participants. All FPG and lipid indexes were analysed enzymatically on a Hitachi 7020 automatic biochemical analyser using commercial reagents (Kangxiang Medical Appliances, Shanghai, PR of China). Intra-assay and interassay coefficients of variation were less than $2 \%$ and $4 \%$, respectively. In our study, hyperglycaemia was defined as the following: $\mathrm{FPG} \geq 100 \mathrm{mg} / \mathrm{dL}(5.6 \mathrm{mmol} / \mathrm{L})$ or a self-reported history of diabetes. Diabetes was defined as FPG $\geq 126 \mathrm{mg} / \mathrm{dL}(7.0 \mathrm{mmol} / \mathrm{L})$ or self-reported history of diabetes.

Serum soluble corin was reported to be stable in blood samples frozen at $-80^{\circ} \mathrm{C}$. We used a quantikine human corin immunoassay (R\&D Systems, Inc, Minneapolis, Minnesota, USA-Catalog: DCRN00) to examine soluble corin levels in serum. All the samples were processed in a duplicate assay. A standard curve was constructed and corin concentrations of unknown samples were determined from the standard curve. Intra-assay and interassay coefficients of variation were less than $2.7 \%$ and $6.3 \%$, respectively.

\section{Statistical analysis}

Statistical analysis was conducted using SAS statistical software (V.9.1, Cary, North Carolina, USA). Baseline characteristics were presented in participants with and without hyperglycaemia by sex. Comparisons in baseline characteristics between the two groups were performed using a Student's t test, Wilcoxon rank-sum test, or the $\chi^{2}$ test, as appropriate. The average level of serum soluble corin was compared between the two groups, using a Wilcoxon rank-sum test for lacking a normal distribution. Univariate and multivariate non-conditional logistic regression models were performed to assess the association between serum soluble corin and hyperglycaemia in men and women, respectively. In the current analysis, study participants were first categorised into quartiles of serum soluble corin. ORs and 95\% CIs of hyperglycaemia were calculated for upper quartiles of corin with the lowest quartile as a reference. Trends in the ORs of hyperglycaemia across increasing corin categories were determined, modelling corin category as an ordinal variable. The potential covariates such as age, cigarette smoking, alcohol consumption, SBP, BMI, TC and HDL-C, were included in the multivariate model. Then, participants were categorised into two groups: low 
corin group and high corin group (divided by the median of serum soluble corin). The rationality is the similar prevalence of hyperglycaemia in the first two quartiles and the up two quartiles. The OR and 95\% CI of hyperglycaemia associated with the high corin group compared with low corin group was also determined in men and women. A two-tailed $\mathrm{p}$ value less than 0.05 was considered statistically significant.

\section{Sensitivity analysis}

We previously found an increased serum soluble corin in hypertensive individuals, ${ }^{16}$ indicating a probable modifiable effect on the association between serum soluble corin and hyperglycaemia. To examine whether hypertension affects the association, participants with hypertension were excluded.

\section{RESULTS}

\section{Baseline characteristics}

A total of 2498 (962 men and 1536 women) participants were included in the current analysis. The average age was 52.7 years and ranged from 30 to 80 years. In men, there were $572(59.46 \%)$ cigarette smokers, 421 $(43.76 \%)$ alcohol consumers and $340(35.34 \%)$ individuals with hyperglycaemia including $101(10.50 \%)$ with diabetes. In women, there were $10(0.65 \%)$ cigarette smokers, $44(2.86 \%)$ alcohol consumers and 432 (28.13\%) individuals with hyperglycaemia including 116 $(7.55 \%)$ with diabetes. The median level of serum soluble corin was $2174.5 \mathrm{pg} / \mathrm{mL}$ with a range of 503.0 $5335.7 \mathrm{pg} / \mathrm{mL}$ in men, and $1515.1 \mathrm{pg} / \mathrm{mL}$ with a range of $373.4-3448.8 \mathrm{pg} / \mathrm{mL}$ in women. Serum soluble corin was higher in men than in women $(p<0.001)$. The interaction $\mathrm{p}$ value of corin and gender was 0.0017 . The characteristics of participants are presented in table 1 . In men, participants with hyperglycaemia were more likely to be older and had higher levels of BMI, WC, SBP, DBP, TC, TG and LDL-C (all $\mathrm{p}$ values $<0.05$ ). The percentage of cigarette smoking was lower in participants with hyperglycaemia than in those without hyperglycaemia $(p<0.001)$. The median level of serum soluble corin was $2306.9 \mathrm{pg} / \mathrm{mL}$ in men with hyperglycaemia, significantly higher than that in men without hyperglycaemia $(2076.5 \mathrm{pg} / \mathrm{mL}) \quad(\mathrm{p}<0.001)$. In women, participants with hyperglycaemia were more likely to be older and had higher levels of BMI, WC, SBP, DBP, TC, TG and LDL-C, and lower HDL-C (all p values <0.001), compared with those without hyperglycaemia. The median level of serum soluble corin was also significantly higher in women with hyperglycaemia than in those without hyperglycaemia (1563.9 vs $1489.2 \mathrm{pg} / \mathrm{mL}$, $\mathrm{p}<0.001)$.

\section{Association of hyperglycaemia with serum soluble corin}

When participants were categorised into four groups according to quartiles of serum soluble corin in men and women, respectively, ORs of hyperglycaemia for

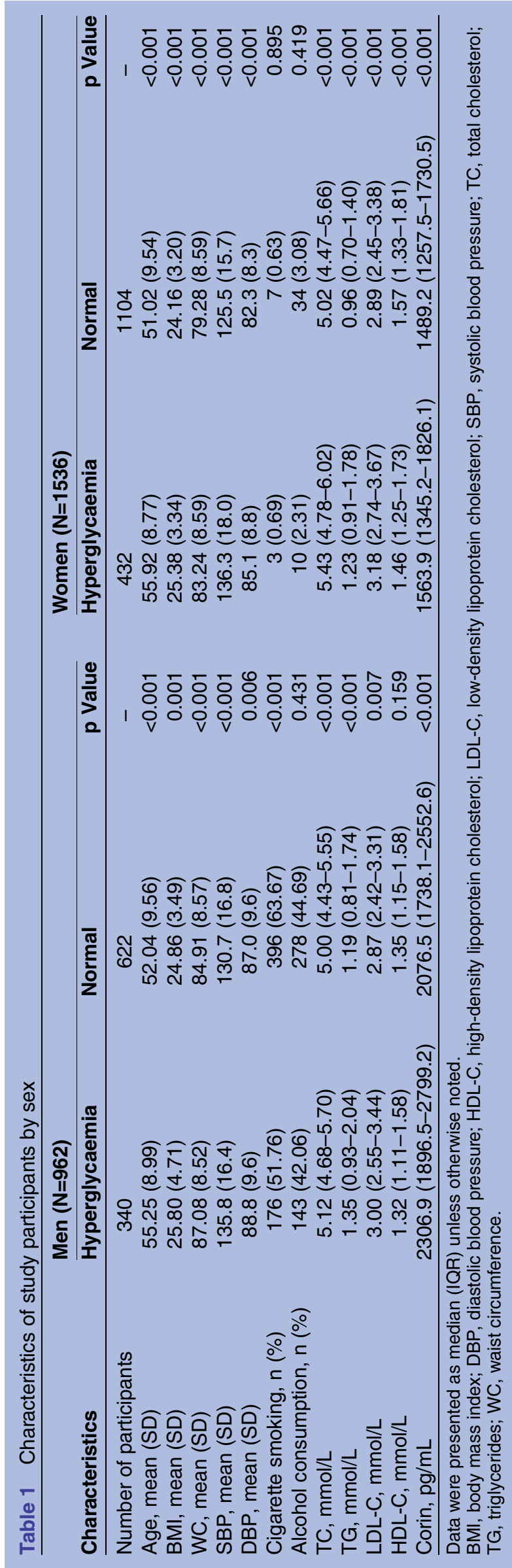


upper quartiles were calculated with the lowest quartile as a reference. The results are presented in table 2 . In women, the univariate analysis showed a significant OR of hyperglycaemia for participants in the third $(\mathrm{OR}=1.51, \mathrm{p}=0.012)$ and fourth $(\mathrm{OR}=1.79, \mathrm{p}<0.001)$ quartile compared with those in the lowest quartile. After multivariable adjustment, these ORs were still over 1 but the $p$ value were not significant. ORs of hyperglycaemia positively increased with serum soluble corin quartiles after adjustment for age, cigarette smoking, alcohol consumption, SBP, BMI, TC and HDL-C ( $p$ for trend $=0.050)$. Similarly, among men, we found a significant unadjusted OR of hyperglycaemia for participants in the third $(\mathrm{OR}=1.54, \mathrm{p}=0.025)$ and fourth $(\mathrm{OR}=2.07$, $\mathrm{p}<0.001)$ quartile of serum soluble corin compared with those in the lowest quartile. In the multivariate analysis, participants in the fourth quartile of serum soluble corin still had significantly increased odds of hyperglycaemia $(\mathrm{OR}=1.93, \mathrm{p}=0.002)$, compared with those in the lowest quartile. Moreover, ORs of hyperglycaemia significantly increased with serum soluble corin levels after multivariate adjustment ( $\mathrm{p}$ for trend $<0.001$ ).

Notably, the prevalence of hyperglycaemia distributed in quartiles of serum soluble corin was $20.59 \%, 19.41 \%$, $27.65 \%$ and $32.35 \%$ in men, and $20.14 \%, 21.99 \%$, $27.31 \%$ and $30.56 \%$ in women (table 2). Obviously, hyperglycaemia was equally distributed in the lower and upper two quartiles individually. As a result, we further divided participants into two groups according to the median level of serum soluble corin: low and high corin groups. The OR of hyperglycaemia was calculated for participants in the high corin group compared with those in the low corin group; it is presented in table 3. The univariate analysis showed increased odds of hyperglycaemia in participants with high corin compared with participants with low corin among men $(\mathrm{OR}=1.87$, $\mathrm{p}<0.001)$ and women $(\mathrm{OR}=1.55, \mathrm{p}<0.001)$. After multivariate adjustment, the significantly increased odds of hyperglycaemia persisted where the OR of hyperglycaemia for participants with high corin was 1.66 $(\mathrm{p}<0.001)$ in men and $1.27(\mathrm{p}=0.055)$ in women, compared with participants with low corin.

\section{Results of sensitivity analysis}

As shown in table 4, sensitivity analysis after excluding hypertensive individuals showed an increased prevalence of hyperglycaemia in the high corin group compared with low corin group among men and women. Although we did not observe a significant OR of hyperglycaemia in the high corin group compared with low corin group, the point estimate of the ORs were similar to the results in total participants in men and women. This indicated that hypertension did not affect the association between serum soluble corin and hyperglycaemia.

\section{DISCUSSION}

Corin is a type II transmembrane serine protease highly expressed in the heart. ${ }^{6} 7$ Recently, corin was found to play a physiological role in the conversion of the inactive precursors of atrial natriuretic peptides to mature active forms. ${ }^{8}{ }^{9}$ Large cross-sectional and prospective studies found that a decreased atrial natriuretic peptide level in the circulation was associated with an increased risk for diabetes, ${ }^{11} 19{ }^{20}$ suggesting that deficient activation of atrial natriuretic peptides might be a risk factor of diabetes. Therefore, as a physiological activator of atrial natriuretic peptides, corin may play a potential role in diabetes. Moreover, soluble corin in the circulation is detectable and was found to have the same activity as the membrane-bound corin in activation of atrial natriuretic peptides. ${ }^{21}$ If so, soluble corin in the circulation is hypothesised to be decreased in individuals with hyperglycaemia. To test this hypothesis, we conducted a crosssectional study designed to explore the association between serum soluble corin and prevalent hyperglycaemia in 2498 adults in Suzhou, China. Our results showed a raised level of serum soluble corin in

Table 2 ORs and $95 \% \mathrm{Cl}$ of hyperglycaemia associated with quartiles of serum corin in men and women

\begin{tabular}{|c|c|c|c|c|c|}
\hline \multirow{2}{*}{$\begin{array}{l}\text { Corin (pg/mL) } \\
\text { quartiles }\end{array}$} & \multirow[b]{2}{*}{ Hyperglycaemia (\%) } & \multicolumn{2}{|l|}{ Unadjusted } & \multicolumn{2}{|l|}{ Adjusted* } \\
\hline & & OR (95\% Cl) & p Value & OR (95\% Cl) & p Value \\
\hline \multicolumn{6}{|l|}{ Men } \\
\hline 503.0-1785.9 & 70 (20.59) & 1.00 (reference) & & 1.00 (reference) & \\
\hline $1786.0-2174.5$ & $66(19.41)$ & $0.92(0.62$ to 1.36$)$ & 0.665 & 0.99 (0.65 to 1.49$)$ & 0.942 \\
\hline $2174.6-2646.7$ & $94(27.65)$ & 1.54 (1.06 to 2.26$)$ & 0.025 & $1.44(0.97$ to 2.15$)$ & 0.073 \\
\hline $2646.8-5335.7$ & $110(32.35)$ & 2.07 (1.42 to 3.02 ) & $<0.001$ & 1.93 (1.28 to 2.93$)$ & 0.002 \\
\hline$p$ Value for trend & & & $<0.001$ & & $<0.001$ \\
\hline \multicolumn{6}{|l|}{ Women } \\
\hline 373.4-1280.0 & $87(20.14)$ & 1.00 (reference) & & 1.00 (reference) & \\
\hline $1280.1-1515.1$ & 95 (21.99) & $1.13(0.81$ to 1.58$)$ & 0.460 & $1.08(0.76$ to 1.54$)$ & 0.652 \\
\hline $1515.2-1758.5$ & $118(27.31)$ & 1.51 (1.10 to 2.09$)$ & 0.012 & $1.28(0.91$ to 1.81$)$ & 0.156 \\
\hline $1758.6-3448.8$ & $132(30.56)$ & 1.79 (1.31 to 2.47$)$ & $<0.001$ & 1.36 (0.97 to 1.91$)$ & 0.080 \\
\hline$p$ Value for trend & & & $<0.001$ & & 0.050 \\
\hline
\end{tabular}

*Adjusted for age, systolic blood pressure, cigarette smoking, alcohol consumption, body mass index, total cholesterol and high-density lipoprotein cholesterol. 
Table 3 ORs and $95 \% \mathrm{Cl}$ of hyperglycaemia associated with high corin group compared with low corin group in men and women

\begin{tabular}{|c|c|c|c|c|c|}
\hline \multirow[b]{2}{*}{ Corin level } & \multirow[b]{2}{*}{ Hyperglycaemia (\%) } & \multicolumn{2}{|l|}{ Unadjusted } & \multicolumn{2}{|l|}{ Adjusted } \\
\hline & & OR (95\% Cl) & p Value & OR (95\% Cl) & p Value \\
\hline \multicolumn{6}{|l|}{ Men } \\
\hline Low corin & $136(28.27)$ & 1.00 (reference) & & 1.00 (reference) & \\
\hline High corin & $204(42.41)$ & 1.87 (1.43 to 2.44$)$ & $<0.001$ & 1.66 (1.24 to 2.23$)$ & $<0.001$ \\
\hline \multicolumn{6}{|l|}{ Women } \\
\hline Low corin & $182(23.73)$ & 1.00 (reference) & & 1.00 (reference) & \\
\hline High corin & $250(32.51)$ & 1.55 (1.24 to 1.94$)$ & $<0.001$ & 1.27 (1.00 to 1.61$)$ & 0.055 \\
\hline
\end{tabular}

hyperglycaemia compared with euglycaemia. Logistic regression analysis found that ORs of hyperglycaemia increased with serum soluble corin levels after multivariate adjustment. These findings did not provide population-based supportive evidence for the above hypothesis that soluble corin is decreased in hyperglycaemia. Our findings seemed to show that increased serum soluble corin might be a risk factor or a biomarker for hyperglycaemia in populations.

In the present study, corin in the circulation was examined using the same commercial ELISA assay employed in previous studies. ${ }^{13} 1522{ }^{23}$ We used a serum sample other than plasma to examine corin concentration in the circulation, in consideration of the variation of corin values among plasma samples with different anticoagulants. ${ }^{24}$ The range of corin detected in the individuals without hyperglycaemia in our study was similar to that reported previously. ${ }^{23}{ }^{25}$ We found that there was a significant difference in corin level between men and women, which was consistent with other studies, ${ }^{12} 13$ although the reason why there was an apparent difference between genders was still unknown.

To date, there have been reports that corin concentration in the circulation was decreased in patients with heart failure, ${ }^{13}$ acute coronary syndrome ${ }^{26}$ and osteoporosis, ${ }^{12}$ but increased in women with pregnant hypertension, ${ }^{15}{ }^{27}$ and in individuals with hypertension ${ }^{16}$ and obesity. ${ }^{17}$ However, the mechanisms of the change of corin in these diseases are still a mystery. The varied corin levels in different disease states reflected a complex mechanism related to diseases. As a type II transmembrane serine protease, corin activity may be varied in normal and abnormal tissues. A previous study reported that corin expression was upregulated, whereas corin activity did not increase in failing heart tissues. ${ }^{28}$ This finding indicated that corin activity was decreased but corin concentration was increased in heart failure. Confusingly, circulating plasma soluble corin levels were decreased in patients with heart failure. ${ }^{13}$ In contrast, corin concentration was increased in tissues of failing heart. Does circulating soluble corin concentration stay consistent with corin level in tissues? Maybe in heart failure, corin shedding from the heart was downregulated or soluble corin clearance was accelerated. In addition, the contrast variations of corin level in the circulation and tissues indicated that corin may have other unknown functions or that there are some other unknown factors that could influence corin levels. ${ }^{27} \mathrm{We}$ found that the ORs of upper quartiles with the lowest quartile as a reference attenuated after multivariate adjustment in both men and women, indicating that these adjusted factors could affect the association of corin and hyperglycaemia.

Notably, the prevalence of hyperglycaemia was equally distributed in the first two quartiles and similar in the last two quartiles of serum soluble corin. Thus, we examined the association of hyperglycaemia with an increased serum soluble corin level. We found significantly increased odds of prevalent hyperglycaemia in participants with an increased serum soluble corin level in men

Table 4 ORs and $95 \% \mathrm{Cl}$ of hyperglycaemia associated with high corin group compared with low corin group in men and women after excluding hypertensive individuals

\begin{tabular}{|c|c|c|c|c|c|}
\hline \multirow[b]{2}{*}{ Corin level } & \multirow[b]{2}{*}{ Hyperglycaemia (\%) } & \multicolumn{2}{|l|}{ Unadjusted } & \multicolumn{2}{|l|}{ Adjusted } \\
\hline & & OR (95\% Cl) & p Value & OR $(95 \% \mathrm{Cl})$ & p Value \\
\hline \multicolumn{6}{|l|}{ Men } \\
\hline Low corin & $54(21.34)$ & 1.00 (reference) & & 1.00 (reference) & \\
\hline High corin & 58 (32.77) & $1.80(1.16-2.77)$ & 0.008 & 1.61 (0.98 to 2.64$)$ & 0.060 \\
\hline \multicolumn{6}{|l|}{ Women } \\
\hline Low corin & 97 (18.2) & 1.00 (reference) & & 1.00 (reference) & \\
\hline High corin & $93(21.83)$ & 1.26 (0.91 to 1.73$)$ & 0.161 & $1.14(0.82$ to 1.58$)$ & 0.440 \\
\hline
\end{tabular}


and women. In addition, we found an increased level of serum soluble corin in hypertensive individuals. ${ }^{16}$ This indicated a probable modifiable effect of hypertension on the association between hyperglycaemia and serum soluble corin. We conducted a sensitivity analysis after excluding the hypertensive individuals and found that the association slightly attenuated, however, with a similar point estimate of OR with the results in total participants. Our findings increased the probability that hyperglycaemia was significantly and positively associated with increased serum soluble corin. However, why corin was increased in individuals with hyperglycaemia in comparison with those without hyperglycaemia remains to be studied in various populations in the future.

To our knowledge, this is the first study to investigate the association between serum soluble corin and hyperglycaemia in a general population. In our study, we excluded participants who had a history of coronary heart disease, stroke or tumours. In addition to serum soluble corin, we obtained major conventional risk factors for diabetes, such as hypertension, blood lipids, BMI, WC and lifestyle factors including alcohol consumption and cigarette smoking. In data analysis, all conventional risk factors obtained were controlled to reduce their confounding effects.

\section{CONCLUSIONS}

We first reported the relationship between serum soluble corin and hyperglycaemia in a large sample of the general population. Our study found an increased level of serum soluble corin in participants with hyperglycaemia, and a significant association of hyperglycaemia with increased serum soluble corin. This study suggests that serum soluble corin may play a potential role in glucose metabolism and might serve as a risk factor or biomarker for hyperglycaemia. Our findings encourage further studies to determine the relationship between serum soluble corin and hyperglycaemia. The findings also produced a new research idea, that of studying the aetiology of diabetes. This study suggests that corin may be a new therapeutic target of diabetes and may have significance in promoting the prevention of diabetes and its clinical treatment.

Acknowledgements The authors are deeply appreciative of the participants in this study, and would like to thank all the staff members for their support and assistance. The study is supported by a Project of the Priority Academic Program Development of Jiangsu Higher Education Institutions of China, and the Suzhou Science and Technology Project (number SS0910 and number SS201333). These institutions had no role in the design, analysis or writing of this article.

Contributors $\mathrm{YL}, \mathrm{HP}, \mathrm{QZ}$ and $\mathrm{YZ}$ designed and performed the study. $\mathrm{YL}, \mathrm{PZ}$, $\mathrm{YT}$ and $\mathrm{XC}$ performed the study. YL and HP analysed the data and wrote the manuscript. HP and $\mathrm{YZ}$ edited the manuscript. All the authors had final approval of the submitted and published version.

Funding A Project of the Priority Academic Program Development of Jiangsu Higher Education Institutions of China, and the Suzhou Science and Technology Project.
Competing interests None declared.

\section{Patient consent Obtained.}

Ethics approval This study was approved by the Soochow University Ethics Committee. Written informed consent was obtained from all study participants.

Provenance and peer review Not commissioned; externally peer reviewed.

Data sharing statement No additional data are available.

Open Access This is an Open Access article distributed in accordance with the Creative Commons Attribution Non Commercial (CC BY-NC 4.0) license, which permits others to distribute, remix, adapt, build upon this work noncommercially, and license their derivative works on different terms, provided the original work is properly cited and the use is non-commercial. See: http:// creativecommons.org/licenses/by-nc/4.0/

\section{REFERENCES}

1. Grundy SM, Benjamin IJ, Burke GL, et al. Diabetes and cardiovascular disease: a statement for healthcare professionals from the American Heart Association. Circulation 1999;100: 1134-46.

2. [No authors listed]. Diabetes mellitus: a major risk factor for cardiovascular disease. A joint editorial statement by the American Diabetes Association; The National Heart, Lung, and Blood Institute; The Juvenile Diabetes Foundation International; The National Institute of Diabetes and Digestive and Kidney Diseases; and The American Heart Association. Circulation 1999;100:1132-3.

3. Xu Y, Wang L, He J, et al., 2010 China Noncommunicable Disease Surveillance Group. Prevalence and control of diabetes in Chinese adults. JAMA 2013;310:948-59.

4. Aguiar EJ, Morgan PJ, Collins CE, et al. Efficacy of the Type 2 Diabetes Prevention Using LifeStyle Education Program RCT. Am J Prev Med 2015. doi: 10.1016/j.amepre.2015.08.020.

5. Utz SW, Williams IC, Jones R, et al. Culturally tailored intervention for rural African Americans with type 2 diabetes. Diabetes Educ 2008;34:854-65.

6. Yan $\mathrm{W}$, Sheng $\mathrm{N}$, Seto $\mathrm{M}$, et al. Corin, a mosaic transmembrane serine protease encoded by a novel cDNA from human heart. J Biol Chem 1999;274:14926-35

7. Pan J, Hinzmann B, Yan W, et al. Genomic structures of the human and murine corin genes and functional GATA elements in their promoters. J Biol Chem 2002;277:38390-8.

8. Wu F, Yan W, Pan J, et al. Processing of pro-atrial natriuretic peptide by corin in cardiac myocytes. J Biol Chem 2002;277:16900-5.

9. Chan JC, Knudson O, Wu F, et al. Hypertension in mice lacking the proatrial natriuretic peptide convertase corin. Proc Natl Acad Sci USA 2005;102:785-90.

10. Ichiki T, Huntley BK, Burnett JC Jr. BNP molecular forms and processing by the cardiac serine protease corin. Adv Clin Chem 2013;61:1-31.

11. Magnusson M, Jujic A, Hedblad B, et al. Low plasma level of atrial natriuretic peptide predicts development of diabetes: the prospective Malmo Diet and Cancer study. J Clin Endocrinol Metab 2012;97:638-45.

12. Zhou H, Liu W, Zhu J, et al. Reduced serum corin levels in patients with osteoporosis. Clin Chim Acta 2013;426:152-6.

13. Dong N, Chen S, Yang J, et al. Plasma soluble corin in patients with heart failure. Circ Heart Fail 2010;3:207-11.

14. Fang $\mathrm{C}$, Shen $\mathrm{L}$, Dong $\mathrm{L}$, et al. Reduced urinary corin levels in patients with chronic kidney disease. Clin Sci (Lond) 2013;124:709-17.

15. Zaki MA, El-Banawy Sel-D, El-Gammal HH. Plasma soluble corin and $\mathrm{N}$-terminal pro-atrial natriuretic peptide levels in pregnancy induced hypertension. Pregnancy Hypertens 2012;2:48-52.

16. Peng $\mathrm{H}$, Zhang $\mathrm{Q}$, Cai $\mathrm{X}$, et al. Association Between High Serum Soluble Corin and Hypertension: a Cross-Sectional Study in a General Population of China. Am J Hypertens 2015;28:1141-9.

17. Peng $\mathrm{H}$, Zhang $\mathrm{Q}$, Shen $\mathrm{H}$, et al. Association between serum soluble corin and obesity in Chinese adults: a cross-sectional study. Obesity (Silver Spring) 2015;23:856-61.

18. Weber MA, Schiffrin EL, White WB, et al. Clinical practice guidelines for the management of hypertension in the community a statement by the american society of hypertension and the international society of hypertension. J Hypertens 2014;32:3-15.

19. Olsen $\mathrm{MH}$, Hansen TW, Christensen MK, et al. N-terminal pro brain natriuretic peptide is inversely related to metabolic cardiovascular 
risk factors and the metabolic syndrome. Hypertension 2005;46:660-6.

20. Wang TJ, Larson MG, Keyes MJ, et al. Association of plasma natriuretic peptide levels with metabolic risk factors in ambulatory individuals. Circulation 2007:115:1345-53.

21. Knappe S, Wu F, Masikat MR, et al. Functional analysis of the transmembrane domain and activation cleavage of human corin: design and characterization of a soluble corin. J Biol Chem 2003;278:52363-70.

22. Dong N, Chen S, Wang W, et al. Corin in clinical laboratory diagnostics. Clin Chim Acta 2012;413:378-83.

23. Ibebuogu UN, Gladysheva IP, Houng AK, et al. Decompensated heart failure is associated with reduced corin levels and decreased cleavage of pro-atrial natriuretic peptide. Circ Heart Fail 2011;4:114-20.
24. Dong N, Dong J, Liu P, et al. Effects of anticoagulants on human plasma soluble corin levels measured by ELISA. Clin Chim Acta 2010;411:1998-2003.

25. Peleg A, Jaffe AS, Hasin Y. Enzyme-linked immunoabsorbent assay for detection of human serine protease corin in blood. Clin Chim Acta 2009;409:85-9.

26. Peleg A, Ghanim D, Vered S, et al. Serum corin is reduced and predicts adverse outcome in non-ST-elevation acute coronary syndrome. Eur Heart J Acute Cardiovasc Care 2013;2:159-65.

27. Cui $\mathrm{Y}$, Wang W, Dong N, et al. Role of corin in trophoblast invasion and uterine spiral artery remodelling in pregnancy. Nature 2012;484:246-50.

28. Chen S, Sen S, Young D, et al. Protease corin expression and activity in failing hearts. Am J Physiol Heart Circ Physiol 2010;299: H1687-92. 